\title{
Transcatheter aortic valve implantation in patients with a small aortic annulus: performance of supra-, intra- and infra-annular transcatheter heart valves
}

\author{
Lisa Voigtländer ${ }^{1,5} \cdot$ Won-Keun Kim ${ }^{2} \cdot$ Victor Mauri $^{3} \cdot$ Alina Goßling $^{1} \cdot$ Matthias Renker $^{2} \cdot$ Atsushi Sugiura $^{4}$. \\ Matthias Linder ${ }^{1,5} \cdot$ Tobias Schmidt $^{3} \cdot$ Niklas Schofer $^{1,5} \cdot$ Dirk Westermann $^{1,5} \cdot$ Hermann Reichenspurner $^{5,6}$. \\ Georg Nickenig ${ }^{4}$. Stefan Blankenberg ${ }^{1,5}$. Christian Hamm ${ }^{2}$. Lenard Conradi ${ }^{5,6}$. Matti Adam ${ }^{3}$. Jan-Malte Sinning ${ }^{4}$. \\ Moritz Seiffert ${ }^{1,5}$ (1)
}

Received: 8 May 2021 / Accepted: 2 August 2021 / Published online: 13 August 2021

(c) The Author(s) 2021

\begin{abstract}
Background A small aortic annulus is associated with increased risk of prosthesis-patient mismatch (PPM) after transcatheter aortic valve implantation (TAVI). Whether specific transcatheter heart valve (THV) designs yield superior hemodynamic performance in these small anatomies remains unclear.

Methods Data from 8411 consecutive patients treated with TAVI from May 2012 to April 2019 at four German centers were retrospectively evaluated. A small aortic annulus was defined as multidetector computed tomography-derived annulus area $<400 \mathrm{~mm}^{2}$. TAVI was performed with a balloon-expanding intra-annular (Sapien-3, $n=288$ ), self-expanding intra-annular (Portico, $n=110$ ), self-expanding supra-annular (Evolut, $n=179$ and Acurate-Neo, $n=428$ ) and mechanically expanding infra-annular (Lotus, $n=64$ ) THV according to local practice. PPM was defined as indexed effective orifice area $\leq 0.85 \mathrm{~cm}^{2} / \mathrm{m}^{2}$.

Results A small annulus was found in 1069 (12.7\%) patients. PPM was detected in 38.3\% overall with a higher prevalence after implantation of a balloon-expanding intra-annular or mechanically expanding infra-annular THV compared to selfexpanding intra- and supra-annular THV. Multivariable analysis linked self-expanding THV (Evolut: Odds ratio [OR] 0.341, Acurate-Neo: OR 0.436, Portico: OR 0.291), postdilatation (OR 0.648) and age (OR 0.968) to lower rates of PPM, while aortic valve calcification was associated with an increased risk (OR 1.001). Paravalvular regurgitation $>$ mild was more frequent after TAVI with self-expanding THV $(p=0.04)$.

Conclusion In this large contemporary multicenter patient population, a substantial number of patients with a small aortic anatomy were left with PPM after TAVI. Self-expanding supra- and intra-annular THV demonstrated superior hemodynamics in these patients at risk, however at the cost of higher rates of residual paravalvular regurgitation.
\end{abstract}

Moritz Seiffert

m.seiffert@uke.de

1 Department of Cardiology, University Heart and Vascular Center Hamburg, Hamburg, Germany

2 Department of Cardiology, Kerckhoff Heart and Thorax Center, Bad Nauheim, Germany

3 Department of Cardiology, Heart Center, University of Cologne, Cologne, Germany

4 Department of Cardiology, University Heart Center, Bonn, Germany

5 German Center for Cardiovascular Research (DZHK), Partner Site Hamburg/Lübeck/Kiel, Hamburg, Germany

6 Department of Cardiovascular Surgery, University Heart and Vascular Center Hamburg, Hamburg, Germany 


\section{Graphic abstract}

\section{Small aortic annulus in $12.7 \%$ of patients}

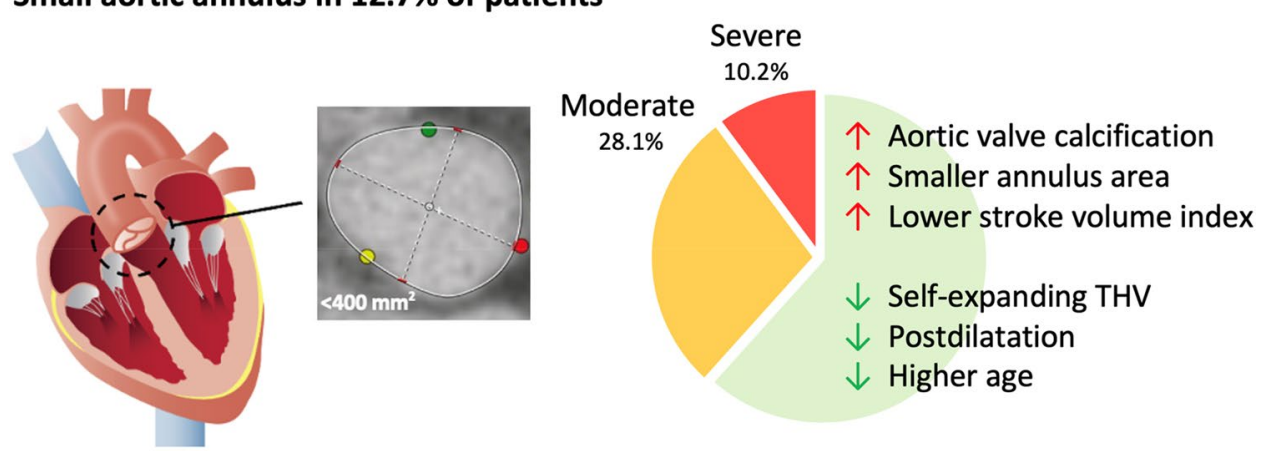

38.3\% with prosthesis-patient mismatch after TAVI

Keywords Transcatheter aortic valve implantation $\cdot$ Aortic stenosis $\cdot$ Small aortic annulus

\section{Introduction}

Patient-prosthesis mismatch (PPM) after aortic valve replacement is associated with increased long-term mortality and morbidity $[1,2]$. Several strategies were developed to minimize the risk of PPM after surgical aortic valve replacement (SAVR), i.e. aortic root enlargement or implantation of sutureless bioprostheses [3, 4]. Although lower rates of PPM were reported after transcatheter aortic valve implantation (TAVI) [5, 6], the prevalence of moderate and severe PPM was described in as many as $35 \%$ of patients [7]. Among other risk factors (i.e. obesity and impaired left ventricular function), a small native aortic annulus was associated with increased rates of PPM [7]. Recent analyses favored supra-annular transcatheter heart valves (THV) for the treatment of patients with severe aortic stenosis and a small aortic annulus (SAA) [8-10]. However, several additional THV designs have become commercially available in the meantime and optimal valve selection for patients with SAA remains unclear.

Aims of our study were (i) to determine the frequency of small aortic anatomies in a consecutive patient population scheduled for TAVI, (ii) to assess the prevalence of prosthesis patient mismatch in these patients, (iii) to detect risk factors for prosthesis patient mismatch and (iv) to compare hemodynamic performance of supra-, intra- and infra-annular THV designs to gain further insights into improved treatment options for these patients at risk.

\section{Methods}

\section{Patient population}

This retrospective analysis included transfemoral TAVI procedures performed between 2012 and 2019 with balloon-expanding (BE: Edwards Lifesciences Sapien-3), self-expanding (SE: Medtronic Evolut/Evolut-R/Pro, Boston Scientific Acurate-Neo, Abbott Vascular Portico) and mechanically expanding (ME: Boston Scientific Lotus) devices at four high-volume centers in Germany: University Heart Center Hamburg, Kerckhoff Heart and Thorax Center Bad Nauheim, University Heart Center Bonn and University hospital Cologne. In accordance with previous studies $[8,9]$, patients with a SAA (defined as annulus area $<400 \mathrm{~mm}^{2}$, measured by multidetector computed tomography (MDCT)) were included. Patients with valve-invalve procedures, treatment of predominant aortic regurgitation and procedures via non-transfemoral access routes were excluded. Patients were divided into five groups according to the implanted THV (Sapien-3, Evolut, Acurate-Neo, Portico and Lotus).

\section{Transcatheter aortic valve implantation}

All cases were reviewed by the local heart team. After written informed consent was obtained, TAVI and selection of THV were performed according to local practice and expertise. Transthoracic echocardiography with assessment of mean valvular gradients, effective orifice areas (EOA) according to the continuity equation and aortic regurgitation were performed before TAVI and at discharge. Baseline 
contrast-enhanced MDCT imaging was analyzed with the 3 mensio software (3mensio Structural Heart, 3mensio Medical Imaging, Maastricht, The Netherlands) with a focus on annulus geometry and landing zone calcification, which contained the aortic valve complex, defined as the region between basal plane and coronary ostium, and left ventricular outflow tract (LVOT), defined as the region from $5 \mathrm{~mm}$ inferior to basal plane [11]. The implantation depth was assessed at the left coronary cusp and non-coronary cusp in the final angiography in a perpendicular annular plane. Implantation depth was defined as the distance between native aortic annulus and the end of the stent frame (inflow) in the LVOT.

\section{Data acquisition and endpoint definitions}

Data acquisition was performed by the local study team, and endpoint assessment was performed by an experienced interventional cardiologist at the local study site. The primary endpoint was the occurrence of moderate or severe PPM after TAVI. PPM was defined according the Valve Academic Research Consortium criteria (VARC-2) as moderate (indexed EOA $(\mathrm{iEOA}) \leq 0.85 \mathrm{~cm} 2)$ and severe $(\mathrm{iEOA} \leq 0.65$ $\mathrm{cm} 2$ ) with correction in obese patients (body mass index $\geqq 30 \mathrm{~kg} / \mathrm{m} 2$; moderate PPM: iEOA $<0.7 \mathrm{~cm} 2 / \mathrm{m} 2$; severe PPM: iEOA $<0.6 \mathrm{~cm}^{2} / \mathrm{m}^{2}$ ) [12]. Secondary endpoints and echocardiographic outcomes were defined according to VARC-2 criteria [12]. All patients provided informed consent to the procedure and data acquisition. Ethics committee approval was obtained according to local requirements. The study was performed in accordance with the 1964 Declaration of Helsinki and its later amendments.

\section{Statistical analysis}

Continuous variables were shown as median (interquartile range $[\mathrm{IQR}]$ ), whereas binary variables were shown as absolute numbers and percentages. For between-group comparisons, the Mann-Whitney test was used for continuous variables and the $c^{2}$ test for binary variables. Uni- and multivariable logistic regression was performed twice: (i) for moderate or severe PPM and (ii) for severe PPM. First, we selected variables with a $p$ value $<0.2$ from Tables 1 and 2. Variables used to derive PPM (e.g. BSA or iEOA) or with significant missings were excluded, and certain variables were added due to clinical relevance. This led to the following set of variables: (i) age, male sex, BMI, prior malignancy, stroke volume index (SVI), annulus area, sizing in the categories "Within normal range", "Oversizing" and "Undersizing", LVOT calcification, AVC calcification, THV groups, mean transaortic gradient and postdilatation to predict moderate or severe PPM and (ii) age, male sex, BMI, NYHA class, SVI, annulus area, sizing in the categories
"Within normal range", "Oversizing" and "Undersizing", LVOT calcification, AVC calcification, THV groups (Sapien-3 as reference, Evolut, Acurate-Neo, Portico and Lotus), mean transaortic gradient and postdilatation. These variables were analyzed by univariate logistic regression analysis and were included in multivariable logistic regression analysis if $p$ values were $<0.05$. The regression was additionally adjusted for the different centers.

\section{Results}

\section{Patient characteristics}

Between May 2012 and April 2019, 8411 consecutive patients underwent transfemoral TAVI for severe aortic stenosis; 1069 patients $(12.7 \%)$ had a SAA and were included in this study. TAVI was performed with Sapien-3 THV in 288 (27\%), with Evolut THV in 179 (17\%), with AcurateNeo THV in 428 (40\%), with Portico THV in $110(10 \%)$ and with Lotus THV in 64 (6\%) patients, respectively.

The majority of the patients were female $(93 \%)$ with a median age of $82.8[79.4,86.1]$ years. Despite a similar risk profile according to the STS PROM score, comorbidities differed significantly among the groups (Table 1). Preprocedural iEOA and mean aortic gradients were comparable, but patients treated with SE THV had significantly smaller annulus areas and perimeters compared to patients treated with BE or ME THV. Calcium distribution also differed among patients: calcification of the aortic valve complex was more severe in the Lotus, Portico and Sapien-3 groups, while LVOT-calcification was particularly severe in patients treated with Lotus THV (Table 1).

\section{Procedural aspects}

Procedures were predominantly performed in local anesthesia or conscious sedation (79.6\%, Table 2). Procedural duration was longer with application of more contrast media in patients treated with Evolut and Lotus THV. Relative oversizing was more frequent in patients treated with SE (Evolut: 44.7 [39.0-57.0] \%, Portico: 30.3 [25.9-36.4] \%, AcurateNeo: 18.7 [11.3-25.9] \%) compared to ME (15.0 [10.4-24.5] $\%)$ and BE THV (8.8 [5.5-18.4] \%, $p<0.001)$. Oversizing exceeding the instructions for use (IFU) was more common in patients treated with Acurate-Neo (44.5\%), Lotus THV (25.0\%) and Sapien-3 (16.4\%) compared to Portico (4.7\%) and Evolut THV $(3.5 \%, p<0.001)$. Predilatation was performed in $53.5 \%$ of procedures overall, while postdilatation was performed particularly after SE vs. BE or ME THV implantation ( $31.5 \%$ vs. $11.4 \%, p<0.001$, Table 2$)$. 
Table 1 Baseline characteristics

\begin{tabular}{|c|c|c|c|c|c|c|}
\hline All $(n=1069)$ & $\begin{array}{l}\text { Sapien 3 } \\
(n=288)\end{array}$ & Evolut $(n=179)$ & $\begin{array}{l}\text { Acurate Neo } \\
(n=428)\end{array}$ & $\begin{array}{l}\text { Portico } \\
\operatorname{THV}(n=110)\end{array}$ & Lotus $(n=64)$ & $p$ value \\
\hline
\end{tabular}

\begin{tabular}{|c|c|c|c|c|c|c|c|}
\hline \multicolumn{8}{|l|}{ Clinical data } \\
\hline Age (years) & $82.8(79.4-86.1)$ & $82.8(78.8-85.9)$ & $83.0(79.8-6.8)$ & $82.4(79.4-85.7)$ & $83.3(80.2-85.8)$ & $83.0(80.0-86.7)$ & 0.52 \\
\hline $\begin{array}{l}\text { Female gender } \\
(\%)\end{array}$ & 994 (93) & $264(91.7)$ & $168(93.9)$ & $398(93.0)$ & $106(96.4)$ & $58(90.6)$ & 0.49 \\
\hline $\operatorname{BSA}\left(\mathrm{m}^{2}\right)$ & $1.7(1.6-1.8)$ & $1.7(1.6-1.8)$ & $1.7(1.6-1.8)$ & $1.7(1.6-1.8)$ & $1.7(1.6-1.8)$ & $1.7(1.6-1.8)$ & 0.22 \\
\hline CAD $(\%)$ & $574(53.8)$ & $164(56.9)$ & $97(54.2)$ & $230(54.0)$ & $56(50.9)$ & 27 (42.9) & $<0.001$ \\
\hline COPD $(\%)$ & $184(17.2)$ & $54(18.8)$ & $34(19.0)$ & $78(18.2)$ & $12(10.9)$ & $6(9.4)$ & $<0.001$ \\
\hline Diabetes $(\%)$ & $266(24.9)$ & $69(24.0)$ & $38(21.2)$ & $110(25.7)$ & $37(33.6)$ & $12(18.8)$ & $<0.001$ \\
\hline Stroke $(\%)$ & $133(12.4)$ & $43(14.9)$ & $15(8.4)$ & $52(12.1)$ & $14(12.7)$ & $9(14.1)$ & $<0.001$ \\
\hline STS PROM (\%) & $4.5(3.1-6.5)$ & $4.5(3.2-6.6)$ & $4.7(3.2-6.5)$ & $4.4(3.2-6.5)$ & $4.9(3.1-6.6)$ & $4.0(3.0-5.2)$ & 0.33 \\
\hline \multicolumn{8}{|c|}{ Echocardiographic and CT data } \\
\hline LVEF $<30 \%$ & $708(66.4)$ & $180(62.7)$ & 133 (74.7) & 294 (68.9) & $74(67.3)$ & $27(42.2)$ & $<0.001$ \\
\hline $\begin{array}{l}\text { Stroke volume } \\
\text { index }\left(\mathrm{ml} / \mathrm{m}^{2}\right)\end{array}$ & $48.0(37.8-66.0)$ & $46.5(36.3-61.0)$ & $41.9(32.6-47.3)$ & $56.0(41.0-69.0)$ & $57.3(42.3-5.0)$ & $41.7(34.6-52.5)$ & $<0.001$ \\
\hline $\operatorname{iEOA}\left(\mathrm{cm}^{2} / \mathrm{m}^{2}\right)$ & $0.4(0.3-0.5)$ & $0.4(0.3-0.5)$ & $0.4(0.3-0.5)$ & $0.4(0.3-0.5)$ & $0.4(0.3-0.4)$ & $0.4(0.3-0.5)$ & 0.34 \\
\hline $\begin{array}{l}\text { Mean gradient } \\
(\mathrm{mmHg})\end{array}$ & $42.0(32.0-53.0)$ & $42.0(31.8-53.0)$ & $40.0(32.0-48.0)$ & $42.0(32.0-54.0)$ & $44.0(32.0-56.0)$ & $44.0(33.1-57.0)$ & 0.12 \\
\hline $\begin{array}{l}\text { CT Annulus } \\
\text { Area }\left(\mathrm{mm}^{2}\right)\end{array}$ & $\begin{array}{l}368.2(342.0,- \\
383.1)\end{array}$ & $\begin{array}{l}376.1(351.9- \\
386.2)\end{array}$ & $\begin{array}{l}359.8(320.9- \\
379.8)\end{array}$ & $\begin{array}{l}368.0(345.4- \\
382.9)\end{array}$ & $\begin{array}{l}361.5(331.9- \\
380.8)\end{array}$ & $\begin{array}{l}370.0(353.9- \\
388.3)\end{array}$ & $<0.001$ \\
\hline $\begin{array}{l}\text { CT Annulus } \\
\text { Perimeter } \\
(\mathrm{mm})\end{array}$ & $69.4(67.0-71.0)$ & $70.0(68.0-71.2)$ & $68.4(64.9-70.1)$ & $69.5(67.2-71.0)$ & $68.8(66.6-70.7)$ & $70.0(68.5-71.3)$ & $<0.001$ \\
\hline $\begin{array}{l}\text { AVC calcifica- } \\
\text { tion }\left(\mathrm{mm}^{3}\right)\end{array}$ & $\begin{array}{l}399.0(227.2- \\
623.7)\end{array}$ & $\begin{array}{l}454.5(272.9- \\
716.8)\end{array}$ & $\begin{array}{l}341.0(190.8- \\
579.7)\end{array}$ & $\begin{array}{l}355.8(177.3- \\
557.5)\end{array}$ & $\begin{array}{l}472.7(271.3- \\
681.5)\end{array}$ & $\begin{array}{l}573.3(297.5- \\
877.7)\end{array}$ & $<0.001$ \\
\hline $\begin{array}{l}\text { LVOT calcifica- } \\
\text { tion }\left(\mathrm{mm}^{3}\right)\end{array}$ & $5.0(0-35.1)$ & $10.0(0-44.2)$ & $12.1(0.1-76.7)$ & $0.4(0-16.3)$ & $5.3(0-32.6)$ & $22.1(0.1-82.4)$ & $<0.001$ \\
\hline
\end{tabular}

$A V C$ aortic valve complex, $B S A$ body surface area, $C A D$ coronary artery disease, $C O P D$ chronic obstructive lung disease, $C T$ computed tomography, $i E O A$ indexed effective orifice area, $L V E F$ left ventricular ejection fraction, $L V O T$ left ventricular outflow tract

\section{Echocardiographic and clinical outcome}

Echocardiographic and clinical outcomes are reported in Table 3. iEOA was larger and mean valvular gradients were lower after TAVI with SE compared to patients treated with $\mathrm{BE}$ and ME THV. More than mild PVL was observed in 7.0\% (Acurate-Neo), 5.5\% (Portico), 3.9\% (Evolut), 2.4\% (Sapien-3) and $1.6 \%$ (Lotus), respectively ( $p=0.04)$.

Peri- and postprocedural complications were similar, except for lower rates of major vascular complications in patients treated with Sapien-3 (4.9\%) and Evolut (2.2\%) compared to Acurate-Neo (10.3\%), Portico (9.1\%) and Lotus THV $(9.4 \%, p=0.003)$ and significant differences in permanent pacemaker implantations after TAVI. Patients treated with Lotus THV had the highest rates of permanent pacemaker implantations (27.6\%) and patients treated with supraannular self-expanding THV (Evolut: 9.8\%, Acurate-Neo: $10.6 \%$ ) had lower permanent pacemaker rates compared to patients treated with intra-annular self- or balloon-expanding THV (Sapien-3: 16.5\%, Portico: 17.8\%, $p=0.001$ ). 30-day and 12 -month mortality rates were $3.2 \%$ and $9.9 \%$, respectively, without differences between the THV groups.

\section{Prosthesis-patient mismatch}

The prevalence of PPM was $38.3 \%$ overall (moderate PPM: 28.1\% and severe PPM: 10.2\%) (Fig. 1). Patients treated with Sapien-3 and Lotus THV had higher rates of PPM (Sapien-3: 56.5\%, Lotus: $38.9 \%$ ) compared to patients treated with Evolut (30.7\%), Acurate-Neo (32.6\%) and Portico THV (25.5\%, $p<0.001)$. Severe PPM occurred most frequently after Lotus (22.2\%) and Sapien-3 (15.8\%) implantation. In patients treated with Evolut, Acurate-Neo and Portico THV, rates of severe PPM were $8.8 \%, 7.4 \%$ and $4.4 \%$.

Patients with severe PPM had a larger body surface area, smaller SVI and iEOAs, higher transvalvular gradients and more severe aortic valve calcification at baseline $(p<0.001$, Table S1). Postdilatation was less common in patients with PPM (severe PPM: $18.7 \%$, moderate PPM: $21.1 \%$, no PPM: $29.3 \%, p=0.014$, Table S2). Clinical outcomes were comparable in patients with and without PPM; however, a trend 
Table 2 Procedural aspects

\begin{tabular}{|c|c|c|c|c|c|c|c|}
\hline & All $(n=1069)$ & $\begin{array}{l}\text { Sapien } 3 \\
(n=288)\end{array}$ & Evolut $(n=179)$ & $\begin{array}{l}\text { Acurate Neo } \\
(n=428)\end{array}$ & $\begin{array}{l}\text { Portico } \\
(n=110)\end{array}$ & Lotus $(n=64)$ & $p$ value \\
\hline THV design & & $\begin{array}{l}\mathrm{BE} \\
\text { intra-annular }\end{array}$ & $\begin{array}{l}\text { SE } \\
\text { supra-annular }\end{array}$ & $\begin{array}{l}\text { SE } \\
\text { supra-annular }\end{array}$ & $\begin{array}{l}\text { SE } \\
\text { intra-annular }\end{array}$ & $\begin{array}{l}\text { ME } \\
\text { infra-annular }\end{array}$ & \\
\hline $\begin{array}{l}\text { Median THV size } \\
(\mathrm{mm})\end{array}$ & $23.0(23.0-25.0)$ & $23.0(23.0-23.0)$ & $26.0(26.0-26.0)$ & $\begin{array}{c}\text { S: } 342(79.9 \%) \mathrm{M}: \\
86(20.1 \%) \mathrm{L}: 0\end{array}$ & $\begin{array}{l}25.0(23.0- \\
25.0)\end{array}$ & $23.0(23.0-23.0)$ & $<0.001$ \\
\hline \multicolumn{8}{|l|}{$\begin{array}{l}\text { Sizing (according } \\
\text { to IFU) }\end{array}$} \\
\hline Undersizing (\%) & $26(2.5)$ & $0(0)$ & $21(12.4)$ & $0(0)$ & $5(4.7)$ & $0(0)$ & $<0.001$ \\
\hline $\begin{array}{l}\text { Within normal } \\
\text { range }(\%)\end{array}$ & $750(72.3)$ & $225(83.6)$ & $143(84.1)$ & $237(55.5)$ & 97 (90.7) & $48(75.0)$ & $<0.001$ \\
\hline Oversizing (\%) & $261(25.2)$ & $44(16.4)$ & $6(3.5)$ & $190(44.5)$ & $5(4.7)$ & $16(25.0)$ & $<0.001$ \\
\hline $\begin{array}{l}\text { Relative oversiz- } \\
\text { ing }(\%)\end{array}$ & $21.7(10.0-33.4)$ & $8.8(5.5-18.4)$ & $44.7(39.0-57.0)$ & $18.7(11.3-25.9)$ & $\begin{array}{l}30.3(25.9- \\
36.4)\end{array}$ & $15.0(10.4-24.5)$ & $<0.001$ \\
\hline $\begin{array}{l}\text { Local anesthesia / } \\
\text { conscious seda- } \\
\text { tion }(\%)\end{array}$ & $829(78.7)$ & $189(68.0)$ & $153(86.4)$ & $355(83.1)$ & 77 (71.3) & $55(85.9)$ & $<0.001$ \\
\hline $\begin{array}{l}\text { Procedure time } \\
\text { (min) }\end{array}$ & $52.0(35.0-75.0)$ & $52.5(32.0-80.1)$ & $61.0(47.9-86.1)$ & 41.5 (31.0-65.6) & $\begin{array}{l}50.0(37.9- \\
70.0)\end{array}$ & $\begin{array}{l}83.0(57.2- \\
109.6)\end{array}$ & $<0.001$ \\
\hline $\begin{array}{l}\text { Contrast media } \\
(\mathrm{ml})\end{array}$ & $\begin{array}{l}115.0(80.0- \\
164.1)\end{array}$ & $\begin{array}{l}102.5(70.0- \\
150.6)\end{array}$ & $\begin{array}{l}140.5(117.8- \\
180.0)\end{array}$ & $95.0(70.0-140.0)$ & $\begin{array}{l}136.0(100.0- \\
200.2)\end{array}$ & $\begin{array}{l}143.0(110.8- \\
212.2)\end{array}$ & $<0.001$ \\
\hline Predilatation (\%) & $570(53.5)$ & $113(39.2)$ & $45(25.1)$ & $294(69.2)$ & $86(78.2)$ & $32(50.8)$ & $<0.001$ \\
\hline Postdilatation (\%) & $266(25.0)$ & $37(12.8)$ & $46(25.7)$ & $134(31.5)$ & $46(41.8)$ & $3(4.8)$ & $<0.001$ \\
\hline
\end{tabular}

$B E$ balloon-expandable, $I F U$ instructions for use, $M E$ mechanically expanding, $S E$ self-expanding, $T H V$ transcatheter heart valve

toward higher rates of acute kidney injury was observed in patients with severe PPM (severe PPM: $13.8 \%$, moderate PPM: $8.5 \%$, no PPM: $6.8 \%, p=0.080$, Table S3). Mortality at 30 days and 1 year did not differ significantly between patients with and without PPM (Table S3).

Multivariable analysis identified higher age (OR 0.968), SE THV (Evolut: OR 0.341, Acurate-Neo: OR 0.436, Portico: OR 0.291) and postdilatation (OR 0.648) to be associated with less moderate or severe PPM. Aortic valve complex calcification increased the risk of PPM (OR 1.001, Fig. 2). Severe PPM was observed more often in patients with a smaller annulus area (OR 0.991) and a trend to a lower SVI (OR 0.985). SE THV was associated with less severe PPM (Fig. 2).

We did not find any association of implantation depth and iEOA in any of the THV platforms assessed (Fig. 3). Evaluation of implant depth by tertiles did not render any association with the occurrence of PPM or PVL (Table S4).

\section{Discussion}

This retrospective multicenter study examined the hemodynamic results and clinical outcomes of five different THV platforms in 1,069 patients with a SAA. The main findings were: (i) $12.7 \%$ of patients treated with TAVI had a SAA $\left(<400 \mathrm{~mm}^{2}\right.$ ), the vast majority being female. (ii) Prosthesis-patient mismatch occurred in $38.3 \%$ of these patients with a significantly lower prevalence after implantation of a SE supra- or intra-annular THV. (iii) Calcification of the aortic valve complex, a smaller aortic annulus area and lower SVI were additionally associated with PPM, and less PPM was observed in older patients and if postdilatation of the THV was performed.

The presence of a SAA in patients with severe aortic stenosis poses a challenge on further management and is particularly common in women [13]. A prevalence of up to $40 \%$ of patients undergoing TAVI was reported for the Asian OCEAN-TAVI-registry [10]. However, these numbers may vary largely with variable definitions and variations in patient populations [14], potentially explaining the difference to the $12.7 \%$ prevalence identified in our multicenter analysis.

The risk of PPM is considerable in these patients, particularly after SAVR [5]. The negative impact of PPM on outcome has been reported in previous studies [2, 15]. A meta-analysis comprising 27,186 patients after SAVR found moderate and severe PPM to significantly increase all-cause mortality over a long-term follow-up of more than five years (moderate PPM: HR 1.19, 95\% CI 1.07-1.33; severe PPM: $H R=1.84,95 \%$ CI 1.38-2.45) [15]. Potentially due to smaller patient numbers and shorter follow-up, we were 
Table 3 Clinical outcomes

$$
\text { All }(n=1069) \quad \text { Sapien } 3(n=288) \quad \text { Evolut }(n=179) \quad \text { Acurate Neo }
$$

Portico $(n=110) \quad$ Lotus $(n=64) \quad p$ value $(n=428)$

\begin{tabular}{|c|c|c|c|c|c|c|c|}
\hline \multicolumn{8}{|c|}{ Echocardiographic outcome } \\
\hline Moderate PPM & $243(28.1)$ & $93(40.7)$ & $28(21.9)$ & $95(25.2)$ & $20(21.1)$ & $7(16.7)$ & $<0.001$ \\
\hline Severe PPM & $91(10.2)$ & $38(15.8)$ & $12(8.8)$ & $26(7.4)$ & $4(4.4)$ & $11(22.2)$ & $<0.001$ \\
\hline $\operatorname{iEOA}\left(\mathrm{cm}^{2} / \mathrm{m}^{2}\right)$ & $0.9(0.7-1.1)$ & $0.8(0.7-1.0)$ & $1.0(0.8-1.1)$ & $0.9(0.8-1.1)$ & $0.9(0.8-1.1)$ & $0.9(0.6-1.1)$ & $<0.001$ \\
\hline $\begin{array}{l}\text { Mean gradient } \\
(\mathrm{mmHg})\end{array}$ & $10.0(6.8-13.0)$ & $12.2(9.0-16.0)$ & $7.0(4.9-10.2)$ & $9.0(6.0-12.0)$ & $9.0(7.0-11.0)$ & $12.9(9.8-16.0)$ & $<0.001$ \\
\hline PVL $>$ mild $(\%)$ & $51(4.8)$ & $7(2.4)$ & $7(3.9)$ & $30(7.0)$ & $6(5.5)$ & $1(1.6)$ & 0.04 \\
\hline \multicolumn{8}{|c|}{ VARC-2 clinical outcome } \\
\hline $\begin{array}{l}\text { Major vascular } \\
\text { complications } \\
(\%)\end{array}$ & $78(7.3)$ & $14(4.9)$ & $4(2.2)$ & $44(10.3)$ & $10(9.1)$ & $6(9.4)$ & 0.003 \\
\hline $\begin{array}{l}\text { Acute kidney } \\
\text { injury }(\%)^{\mathrm{a}}\end{array}$ & $84(8.3)$ & $20(8.3)$ & $18(10.3)$ & $32(7.6)$ & $11(10.0)$ & $3(4.8)$ & 0.63 \\
\hline $\begin{array}{l}\text { Major Bleeding } \\
(\%)\end{array}$ & $67(6.3)$ & $17(5.9)$ & $5(2.8)$ & $30(7.0)$ & $9(8.2)$ & $6(9.4)$ & 0.21 \\
\hline $\begin{array}{l}\text { Permanent pace- } \\
\text { maker implanta- } \\
\text { tion }(\%)\end{array}$ & $134(13.8)$ & $43(16.5)$ & $16(9.8)$ & $41(10.6)$ & $18(17.8)$ & $16(27.6)$ & 0.001 \\
\hline $\begin{array}{l}\text { Disabling Stroke } \\
(\%)\end{array}$ & $8(0.7)$ & $1(0.3)$ & $2(1.1)$ & $3(0.7)$ & $1(0.9)$ & $1(1.6)$ & 0.81 \\
\hline $\begin{array}{l}\text { Reintervention } \\
(\%)^{\mathrm{b}}\end{array}$ & $3(0.3)$ & $1(0.4)$ & $0(0)$ & $2(0.5)$ & $0(0)$ & $0(0)$ & 0.78 \\
\hline $\begin{array}{l}\text { 30-day mortality } \\
(\%)\end{array}$ & $33(3.2)$ & $9(3.2)$ & $7(4.0)$ & $9(2.2)$ & $5(4.6)$ & $3(4.8)$ & 0.54 \\
\hline $\begin{array}{l}\text { 12-month mortal- } \\
\text { ity }(\%)\end{array}$ & 104 (9.9) & $31(11.0)$ & $16(9.1)$ & $38(9.1)$ & $11(10.1)$ & 8 (12.9) & 0.84 \\
\hline
\end{tabular}

iEOA indexed effective orifice area, $P V L$ paravalvular leakage, $P P M$ prosthesis-patient mismatch

${ }^{a}$ Acute kidney injury `Kidney Disease-Improving Global Outcomes`stadium I-III

${ }^{\mathrm{b}}$ Reasons for reintervention: relevant aortic regurgitation after postdilatation

Fig. 1 Prevalence of moderate and severe PPM with different devices. $p<0.001$ for moderate and severe PPM. PPM prosthesis-patient mismatch

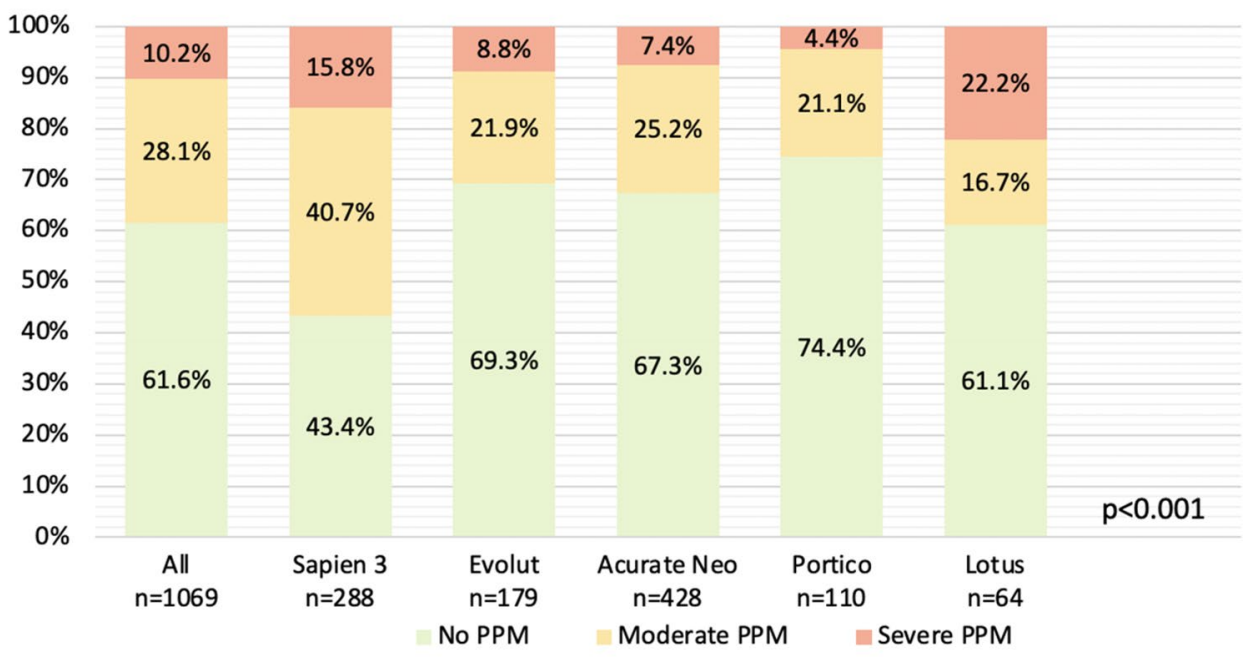

not able to replicate this association in our study population. Longer observation may validate a potential adverse impact on long-term survival.
Due to improved hemodynamics after TAVI compared to SAVR in patients with small aortic anatomies [5], TAVI has increasingly been promoted for the treatment of patients 
Fig. 2 Predictors for moderate and severe (A) and severe (B) PPM. Multivariable analysis for predictors of (A) moderate/ severe and (B) severe prosthesis-patient mismatch. $A V C$ aortic valve complex, $O R$ odds ratio, $T H V$ transcatheter heart valve

\section{A moderate and severe prosthesis-patient mismatch}

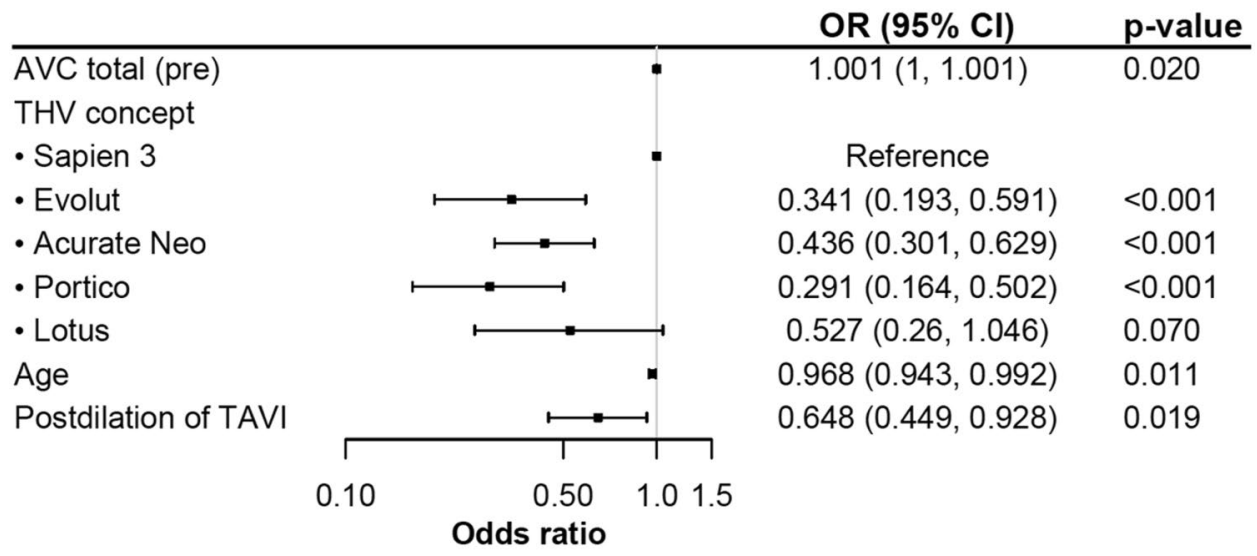

\section{B severe prosthesis-patient mismatch}

\begin{tabular}{|c|c|c|c|c|c|}
\hline & & & & OR (95\% Cl) & p-value \\
\hline \multicolumn{6}{|l|}{ THV concept } \\
\hline \multicolumn{2}{|l|}{ - Sapien 3} & - & & Reference & \\
\hline \multicolumn{2}{|l|}{ • Evolut } & $\longmapsto$ & & $0.401(0.162,0.92)$ & 0.037 \\
\hline \multicolumn{2}{|l|}{ - Acurate $\mathrm{NeO}$} & $\longmapsto$ & & $0.518(0.286,0.935)$ & 0.029 \\
\hline \multicolumn{2}{|l|}{ - Portico } & $\rightarrow$ & & $0.258(0.074,0.699)$ & 0.016 \\
\hline \multicolumn{2}{|l|}{ • Lotus } & & $\longrightarrow$ & $1.481(0.615,3.36)$ & 0.36 \\
\hline \multicolumn{2}{|l|}{ Stroke Volume Index } & - & & $0.985(0.97,1)$ & 0.056 \\
\hline \multirow[t]{3}{*}{ Annulus area (pre) } & & - & & $0.991(0.985,0.998)$ & 0.0076 \\
\hline & $\Gamma$ & 11 & $\neg$ & & \\
\hline & 0.05 & $\begin{array}{cc}0.30 & 1.00\end{array}$ & 3.50 & & \\
\hline
\end{tabular}

at risk to avoid PPM. Except for the presence of a SAA, however, risk factors for PPM after TAVI in these patients remain largely unclear. In addition to THV design, we found calcification of the aortic valve complex and younger age to be associated with moderate or severe PPM while patients with postdilatation after TAVI were at lower risk.

Severe PPM was linked to a lower SVI, a smaller annulus area and-again - to the THV design. Reduced left ventricular ejection fraction is a known risk factor for PPM [16] and supports our findings on low SVI. This is of clinical relevance as patients with PPM and reduced left ventricular function have particularly impaired outcomes [17]. Younger age as a risk factor for PPM has been described before [5]. However, the reason for this still remains unclear.

Our main finding was that SE THV design was independently associated with less PPM which was robust among several multivariate analyses. The hemodynamic advantage of a SE supra-annular THV (Acurate-Neo) over BE intra-annular THV (Sapien-3) in patients with a SAA was reported before [8]. The TAVI-SMALL registry recently demonstrated similar PPM rates with three SE THV platforms (Evolut/Pro, Acurate and Portico) [9] which were in line with the prevalence observed in our analysis. Beyond that, we compared the performance of 5 current THV platforms to further investigate hemodynamic results in patients with a SAA. Moderate and particularly severe PPM was less frequent after implantation of SE (supra- and intra-annular) THV compared to BE (intra-annular) or ME (infra-annular) devices. Interestingly, we did not observe any differences between SE supra- or intra-annular THV designs, contradicting the idea that supra-annular seating alone yields improved hemodynamics. Even though Sapien-3 and Portico THV both feature intra-annular designs, the latter revealed lower rates of PPM. Whether additional materials (e.g. sealing skirts) impact this aspect remains to be determined. Interestingly, implantation depth alone did not correlate with iEOA or the occurrence of PPM for any of the evaluated THV. Hence, THV design rather than implantation technique may be important to avoid PPM in patients at risk.

Due to its adverse impact on outcomes, further refinement of devices and implantation techniques aims to minimize residual regurgitation [18]. Aortic valve calcification is a well-known risk factor for PVL [11] and our data add a link to PPM, making patients with severely calcified aortic 
Fig. 3 Association of implantation depth and iEOA. iEOA indexed effective orifice area, $L C C$ left coronary cusp, $N C C$ non-coronary cusp

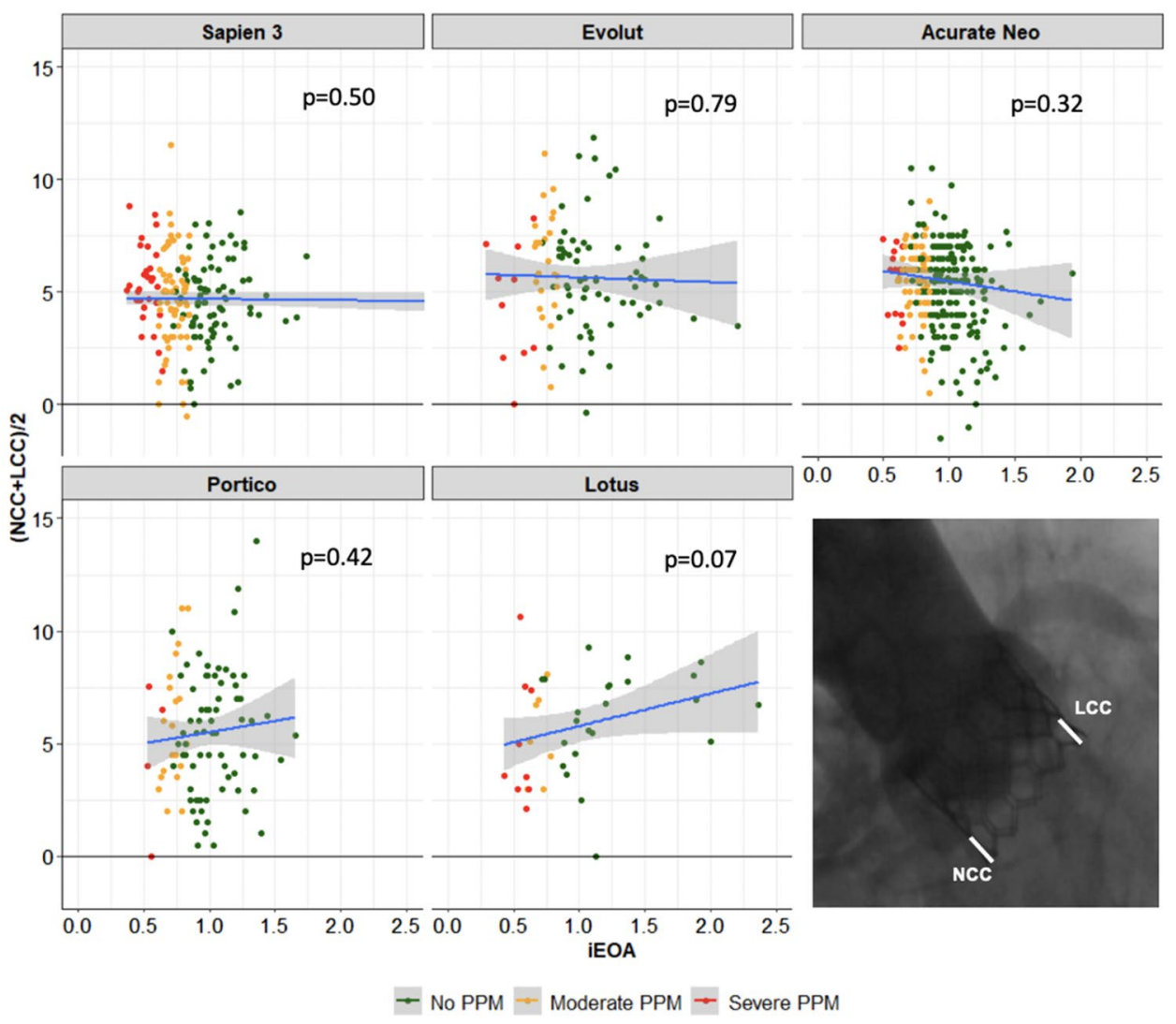

valves and SAA a particularly vulnerable patient population. Relevant PVL was more frequent after implantation of a SE THV — an aspect that must be weighted against the benefits achieved with lower rates of PPM. Several device iterations have recently become commercially available that include specific features to reduce PVL (e.g. Sapien Ultra and Acurate-Neo2) and will need to demonstrate hemodynamic results in future studies.

Peri- and postprocedural complications and 30-day and 12-month mortality rates were mainly similar among THVgroups. Higher rates of major vascular complications after TAVI with Acurate-Neo, Portico and Lotus THV may be due to larger sheath sizes in these procedures or patient-related factors that were not part of this analysis. Rates of permanent pacemaker implantations after TAVI were especially high in patients treated with Lotus THV and, interestingly, patients treated with Sapien-3 and Portico THV had higher rates of new permanent pacemakers compared to patients treated with Evolut and Acurate-Neo THV. This observation contrasts with the findings of previous studies that have shown lower rates of pacemaker implantation after TAVI with balloon-expanding compared with self-expanding THV $[19,20]$. Postdilatation was often performed, particularly after implantation of self-expanding THV with a lower radial force. In our analysis, postdilatation was even associated with lower rates of moderate or severe PPM which was in line with previous observations, suggesting optimization of annular geometry [5]. As postdilatation is not associated with increased complication rates (e.g. annular rupture, valve embolization, central aortic regurgitation or pacemaker implantations) [21], it may be a valuable addition in patients at risk of PPM.

This was a retrospective, multicenter analysis, and results can only be interpreted as hypothesis-generating. Randomized trials comparing different THV in patients with a SAA are on the way and will shed further light on optimal treatment options in these patients. Routine clinical variables and imaging data (echocardiography, MDCT) were assessed and reported by the local investigators in default of a central core laboratory. In addition, the accuracy of the depth measurements is strongly dependent on the quality of the final angiography with sufficient contrast filling of the aortic root. Despite a large number of patients, the prevalence of severe PPM was low so that we evaluated moderate and severe PPM together in order to identify independent predictors for their occurrence. A multivariable model corrected for known confounders and repeatedly identified THV design as strong predictor of PPM. Nevertheless, confounding variables may have been missed. Follow-up duration was not sufficient to document a potential implication of PPM on long-term mortality, and longer observation is warranted in these patients. 


\section{Conclusion}

In this large contemporary TAVI population, a substantial number of patients presented with a SAA. The prevalence of moderate and severe PPM was high, especially in patients treated with BE and ME THV. SE supra- and intra-annular prostheses demonstrated superior hemodynamics and consequently lower rates of PPM but to increased residual PVL. Severe aortic valve calcification, a SAA, low SVI and a lack of postdilatation were furthermore associated with the occurrence of PPM. In patients with severe aortic stenosis and a small annulus, particularly careful evaluation and device selection may yield superior results after TAVI.

Supplementary Information The online version contains supplementary material available at https://doi.org/10.1007/s00392-021-01918-8.

Funding Open Access funding enabled and organized by Projekt DEAL. This research received no grant from any funding agency.

\section{Declarations}

Conflict of interest WKK is a proctor, member of the advisory board and received consulting fees from Abbott, Boston Scientific, Edwards Lifesciences, Meril Life Sciences and Medtronic. MR received lecture fees from Abbott. TS received speaker honoraria and travel support from Edwards Lifesciences, Boston Scientific and Medtronic. NS received travel support from Edwards Lifesciences and St. Jude Medical, speaker honoria and travel support from Boston Scientific. DW received speaker honoria from Astra Zeneca, Bayer, Biotronik, BerlinChemie, Boehringer-Ingelheim, Novartis and Pfizer. $\mathrm{CH}$ is a member of the Medtronic advisory board. LC is a consultant and proctor for Edwards Lifesciences, Boston Scientific and Abbott and member of the speaker's bureau for Edwards Lifesciences, Boston Scientific, Abbott and Medtronic. MA received personal fees from Edwards Lifescience and Boston Scientific, grants and personal fees from Medtronic. JMS is consultant for Abbott, Abiomed, Boston Scientific and Medtronic and receives speaker honoraria from Abbott, Abiomed, Boston Scientific, Edwards Lifesciences and Medtronic. MS served as consultant for JenaValve, received TC from Edwards Lifesciences, Symetis, Boston Scientific and Biotronik and received speaking honoraria from Medtronic. All other authors report no conflicts of interest.

Open Access This article is licensed under a Creative Commons Attribution 4.0 International License, which permits use, sharing, adaptation, distribution and reproduction in any medium or format, as long as you give appropriate credit to the original author(s) and the source, provide a link to the Creative Commons licence, and indicate if changes were made. The images or other third party material in this article are included in the article's Creative Commons licence, unless indicated otherwise in a credit line to the material. If material is not included in the article's Creative Commons licence and your intended use is not permitted by statutory regulation or exceeds the permitted use, you will need to obtain permission directly from the copyright holder. To view a copy of this licence, visit http://creativecommons.org/licenses/by/4.0/.

\section{References}

1. Dayan V, Vignolo G, Soca G et al (2016) Predictors and outcomes of prosthesis-patient mismatch after aortic valve replacement. JACC Cardiovasc Imaging 9:924-933. https://doi.org/10.1016/j. jcmg.2015.10.026

2. Herrmann HC, Daneshvar SA, Fonarow GC et al (2018) Prosthesis-patient mismatch in patients undergoing transcatheter aortic valve replacement. J Am Coll Cardiol 72:2701-2711. https://doi. org/10.1016/j.jacc.2018.09.001

3. Yu W, Tam DY, Rocha RV et al (2019) Aortic root enlargement is safe and reduces the incidence of patient-prosthesis mismatch: a meta-analysis of early and late outcomes. Can J Cardiol 35:782790. https://doi.org/10.1016/J.CJCA.2019.02.004

4. Shalabi A, Spiegelstein D, Sternik L et al (2016) Sutureless versus stented valve in aortic valve replacement in patients with small annulus. Ann Thorac Surg 102:118-122. https://doi.org/ 10.1016/J.ATHORACSUR.2016.01.003

5. Pibarot P, Weissman NJ, Stewart WJ et al (2014) Incidence and sequelae of prosthesis-patient mismatch in transcatheter versus surgical valve replacement in high-risk patients with severe aortic stenosis: a PARTNER Trial Cohort-A Analysis. J Am Coll Cardiol 64:1323-1334. https://doi.org/10.1016/J.JACC.2014.06.1195

6. Seoudy H, Güßefeld N, Frank J et al (2019) Incidence and impact of prosthesis-patient mismatch following transcatheter aortic valve implantation. Clin Res Cardiol 108:660-668. https://doi. org/10.1007/s00392-018-1394-0

7. Takagi H, Umemoto T (2016) Prosthesis-patient mismatch after transcatheter aortic valve implantation. Ann Thorac Surg 101:872-880. https://doi.org/10.1016/J.ATHORACSUR.2015.11. 048

8. Mauri V, Kim WK, Abumayyaleh M et al (2017) Short-term outcome and hemodynamic performance of next-generation selfexpanding versus balloon-expandable transcatheter aortic valves in patients with small aortic annulus: a multicenter propensitymatched comparison. Circ Cardiovasc Interv. https://doi.org/10. 1161/CIRCINTERVENTIONS.117.005013

9. Regazzoli D, Chiarito M, Cannata F et al (2020) Transcatheter self-expandable valve implantation for aortic stenosis in small aortic annuli. JACC Cardiovasc Interv 13:196-206. https://doi. org/10.1016/j.jcin.2019.08.041

10. Hase H, Yoshijima N, Yanagisawa R et al (2020) Transcatheter aortic valve replacement with Evolut $\mathrm{R}$ versus Sapien 3 in Japanese patients with a small aortic annulus: The OCEAN-TAVI registry. Catheter Cardiovasc Interv. https://doi.org/10.1002/ccd. 29259

11. Seiffert M, Fujita B, Avanesov M et al (2016) Device landing zone calcification and its impact on residual regurgitation after transcatheter aortic valve implantation with different devices. Eur Hear J Cardiovasc Imaging 17:576-584. https://doi.org/10.1093/ ehjci/jev174

12. Kappetein AP, Head SJ, Généreux P et al (2013) Updated standardized endpoint definitions for transcatheter aortic valve implantation: The Valve Academic Research Consortium- 2 consensus document*. J Thorac Cardiovasc Surg 145:6-23. https://doi.org/ 10.1016/j.jtcvs.2012.09.002

13. Mihos CG, Klassen SL, Yucel E (2018) Sex-specific considerations in women with aortic stenosis and outcomes after transcatheter aortic valve replacement. Curr Treat Options Cardiovasc Med 20:52. https://doi.org/10.1007/s11936-018-0651-x 
14. Watanabe Y, Hayashida K, Takayama M et al (2015) First direct comparison of clinical outcomes between European and Asian cohorts in transcatheter aortic valve implantation: the Massy study group vs. the PREVAIL JAPAN trial. J Cardiol 65:112-116. https://doi.org/10.1016/j.jjcc.2014.05.001

15. Head SJ, Mokhles MM, Osnabrugge RLJ et al (2012) The impact of prosthesis patient mismatch on long-term survival after aortic valve replacement: a systematic review and meta-analysis of 34 observational studies comprising 27186 patients with 133141 patient-years. Eur Heart J 33:1518-1529

16. Liao YB, Li YJ, Jun-Li L et al (2017) Incidence, predictors and outcome of prosthesis-patient mismatch after transcatheter aortic valve replacement: a systematic review and meta-analysis. Sci Rep. https://doi.org/10.1038/s41598-017-15396-4

17. Schofer N, Deuschl F, Rübsamen N et al (2019) Prosthesis-patient mismatch after transcatheter aortic valve implantation: prevalence and prognostic impact with respect to baseline left ventricular function. EuroIntervention 14:1648-1655. https://doi.org/10. 4244/eij-d-18-00827
18. Leber AW, Kasel M, Ischinger T et al (2013) Aortic valve calcium score as a predictor for outcome after TAVI using the CoreValve revalving system. Int J Cardiol 166:652-657. https://doi.org/10. 1016/j.ijcard.2011.11.091

19. Alperi A, Faroux L, Muntané-Carol G, Rodés-Cabau J (2021) Meta-analysis comparing early outcomes following transcatheter aortic valve implantation with the evolut versus sapien 3 valves. Am J Cardiol. https://doi.org/10.1016/j.amjcard.2020.10.041

20. Van Belle E, Vincent F, Labreuche J et al (2020) Balloon-expandable versus self-expanding transcatheter aortic valve replacement: a propensity-matched comparison from the FRANCE-TAVI Registry. Circulation. https://doi.org/10.1161/CIRCULATIONAHA. 119.043785

21. Hahn RT, Pibarot P, Leipsic J et al (2018) The effect of postdilatation on outcomes in the PARTNER 2 SAPIEN 3 Registry. JACC Cardiovasc Interv 11:1710-1718. https://doi.org/10.1016/j. jcin.2018.05.035 